\title{
Agricultural Supply Chain Risk Management Under Price and Demand Uncertainty
}

Pritee Ray, Indian Institute of Management Ranchi, India

iD https://orcid.org/0000-0002-0840-0768

\begin{abstract}
Agricultural supply chain (ASC) plays a vital role for sustainability as it is the main source of food supply. ASC encounters more sources of risk due to seasonality, perishability, and weather conditions, which makes the global food security system complex. This paper develops an optimization model for a perishable product supply chain to decide the optimal risk management strategy that maximizes the decision maker's expected profit under demand and price uncertainty. A base-case scenario is considered to show the impact of risk management strategy on performance improvement. The expected profit of the decision maker is obtained for different combination of strategies, and sensitivity analysis is performed to show the impact of perishability on the percentage of improvement from the base case scenario. The results show that backup supplier strategy is very effective during the yield disruption, but it is not as effective during harvest disruption. Hence, a single approach is inadequate to provide solution in all types of risk scenarios; thus, the combination of approaches is most effective.
\end{abstract}

\section{KEYWORDS}

Agriculture Supply Chain, Demand Uncertainty, Optimization, Perishability, Price Uncertainty, Risk Management

\section{INTRODUCTION}

The economy of a country depends on agriculture as it is the primary source of food supplies. The agriculture sector in India accounts for about $17-18 \%$ of its GDP and employs approximately $50 \%$ of the country's workforce (Sunder, 2018). It is an important source for generating demand for industrial goods and services. Besides that, the rural areas are the biggest markets for low-priced, and middlepriced consumer goods, including consumer durables and rural domestic savings, are an important source of resource mobilization (Planning Commission India). The products in the agricultural supply chain have attributes such as perishability, seasonality, and bulkiness, which make the agribusiness supply chains (ASCs) more complicated. Dealing with seasonality requires the appropriate organization of the product as the supply is limited, whereas the demand is throughout the year. ASCs have longer lead times; in turn, it increases the chances of perishability. Furthermore, there is often significant time stress on post-harvest activities as most agricultural products are perishable in nature.

Risk management in the agribusiness supply chain is quite challenging because of the existence of various uncertainties (Jones et al., 2003). For example, Jones et al. (2003) studied Syngenta Seeds, Inc's seed corn supply chain's production planning problem. The production planning seed corn is complicated because of the biological process, during the growing season, which further depends on the weather and insect conditions. Syngenta has developed and implemented a second-chance 
production-planning model to mitigate the production yield uncertainty and demand uncertainty. The supply procedure is linked to biological production, which is influenced by weather changes (e.g., floods, droughts), disease, and pests. Such aspects indicate that both harvest levels and harvest times are subject to uncertainties. During the production stage, risks in food handling and storage make risk management even more complicated than other manufacturing supply chains. The situation even worse if there is uncertainty in demand and price of the product to be sold. Hence, there is also a need to build strategies for the sustainability of the agricultural supply chain (Guma et al., 2018; Anilkumar \& Sridharan, 2019).

Risk management strategies can be classified into either robust or resilient (Behzadi et al., 2018). A robust supply chain is able to resist disruption, while a resilient supply chain can swiftly recover from the disruption and return back to its original form. Most quantitative works in the agricultural supply chain considered multiple-sourcing as a robust strategy to manage supply risk (Boyabatl et al., 2017). However, in recent years, the resilient strategy is also used for managing supply risk (Christopher \& Peck, 2004; 6838-131\& Martel, 2012; Namdar et al., 2018). In ASC, the scope of risk management studies is limited when appropriate measures for perishability are integrated for managing harsh or rare disruptions. Perishability is often modelled as product depreciation, especially in inventory management (Thron et al., 2007). Cai \& Zhou (2014) suggested a resilient strategy to reroute fruit between two markets after a disruption. They modelled perishability using an exponential decay cost, where they incorporated two shelf-life metrics, namely best-before-date and good-untiltime, in a vegetable supply chain when there is a disruption in the main transportation link. Given the perishability is a critical concern in ASC risk management, there is a clear need to consider a variety of more sophisticated perishability functions for developing more realistic quantitative models. Behzadi et al. (2017) considered exponential perishability function in a two-stage stochastic programming model. They provided optimal strategy for mitigating the risks in ASC, but they didn't consider demand and price uncertainty in their model. In the real-world scenario, agri-product have uncertainty in supply, demand and hence price. The authors (Behzadi et al., 2018) investigate market disruption risk by developing a multi-commodity multi-period model with the specific purpose of allocation flexibility in the risk-averseness scenario. However, they did not consider supply and demand-side risk together. This paper addresses the gaps by developing a model that considers both demand and price uncertainty together with supply-side risks.

This paper develops a model that helps the ASC planners to select suitable strategies considering perishability with demand and price uncertainties to maximize his expected profit. Primarily the study focuses on two main supply-side risks: Harvest time disruption and yield disruption. Harvest disruption results in the delay of the crop harvesting, which is more than some usual delays. Yield disruption results in the drastic change in the yield of the crop when compared to the normal yield of that crop (Tan \& Çömden, 2012). The price uncertainty is pivotal under the ASC problem, which involves a fresh produce supply chain. Therefore, the price is assumed to be random. The paper design optimal strategy while analysing the effectiveness of risk management (both robust and resilient) strategies, and compared the performance improvement of different strategies under price and demand uncertainty in the line of Behzadi et al. (2017)' s work. An optimization model is developed, which maximizes the expected profit of the decision-maker while satisfying the constraints such as supply, demand, and price uncertainty, perishability, and transport capacities. In this study, perishability is represented by an exponential function and the demand in the respective locations is modelled as uniform distribution since the demand pattern of the product remains uniform throughout the year (e.g., Tomato). As a whole, we have applied the model to a perishable product supply chain to analyse the effectiveness of robust/resilient strategies under harvest time and yield disruptions considering demand and price uncertainty.

The structure of the paper is given as follows. Section 2 gives a brief literature review. Section 3 describes the problem with the notations used and the assumptions made. The formulation of the model with the objective function of maximizing the expected profit of decision-maker with 
the relevant constraints is given in Section 4. Section 5 illustrates the models through numerical examples followed by managerial insights in Section 6. Section 7 gives the conclusion of the study with limitations and future research directions.

\section{LITERATURE REVIEW}

This paper touches upon the important elements in the agribusiness supply chain risk management, namely: (1) Supply chain risk (2) perishability nature of agriculture product and (3) risk management strategies.

Broadly, supply chain risks can be classified into two types; Macro-risks and micro-risks. It is also defined as catastrophic/disruption and operational risks (Ray \& Jenamani, 2016; Sodhi, Son \& Tang, 2012; Tang, 2006). Macro-risk/ disruption risk is the external or rare event that has a negative influence on businesses. They comprise natural disasters (e.g., earthquakes, floods, hurricanes, cyclones, epidemic outbreak etc.) and man-made disasters (e.g., war, terrorist attack, strikes, currency devaluation, bio-warfare etc.). Supply failure due to the disruptive event is known as supply failure risk. Berger et al. (2004) are the first to discuss the supply failure risk, and they further classified it into three events: Super event, semi-super event and unique event. The authors' used the decisiontree approach for obtaining financial loss and operating costs of working with multiple suppliers considering the super event and unique event. Many studies extended their work, considering different disruptive event scenarios. Based on the probability of disruption and its impact, many studies classified supply risk as low probability with high impact risk, medium probability and moderate impact risk and high probability with low impact risk.

On the other hand, micro-risks point to relatively recurrent and frequent situations such as machine breakdown, quality defects, delay etc. that have arisen directly from the internal functions of companies or partnerships within the entire supply chain. Typically, macro-risks have a far greater negative impact on businesses compared to micro-risks (Iqbal \& Shalij, 2019). Iqbal \& Shalij (2019) consider ornamental fish supply and clustered major supply chain risks into six categories, such as macro-level risk, demand risk, supply risk, quality risk, risk-on asset and infrastructure and financial risk. Many studies in the agriculture supply chain consider high probability with low impact risks such as production and market risks (Komarek et al., 2020). However, a few studies consider low probability with high impact risk, such as rare events. Researchers give attention towards demand-side risks such as selling price or market potential (Wiedenmann \& Geldermann, 2015; Gebreslassie et al., 2012; Kazaz \& Webster, 2011; Mirzapour et al., 2011), supply-side risks such as yield uncertainty, spot market price uncertainty (Boyabatli et al., 2017; Ray \& Jenamani, 2013; Kim et al., 2011) while production and transportation-related failures (Cai \& Zhou, 2014) and unpredictability in yield quality, harvest duration, and maturation time (Tan \& Çomden, 2012) etc. Boyabatli et al. (2017) develop a multi-period model to study the storage capacity investment decisions with periodic processing and inventory decisions of agricultural industries where spot prices and production yield are uncertain. They also investigated the impact of spot price uncertainty on the processor's optimal capacity and profitability and explored various heuristic capacity investment policies. Their findings indicate that planning based on the average yield performs well only when the relative capacity investment cost is high; otherwise, it results in substantial loss of profit. The authors also addressed the importance of spot price uncertainty for capacity planning. Wiedenmann \& Geldermann (2015) design a decision support system for planning of agricultural raw material using a two-stage stochastic programming model. Boyabatli et al. (2017) considered a multi-period model for capacity investment and inventory decisions with uncertainty in spot price and yield. They found that planning based on average yields only works well when the relative investment cost of the capacity is high; otherwise, it results in a substantial loss of profit. Similarly, Tan \& Çomden (2012) develop a methodology to determine the farm areas and the seeding times in single and multiple period cases under supply and demand 
uncertainty. For a detailed review of handling uncertainty and risk in the agricultural supply chain, the readers can refer to Borodin et al. (2016) and Behzadi et al. (2018).

All of the papers, as mentioned earlier, superficially investigate perishability. However, perishability is modelled as the depreciation of the product, especially in inventory management (Thron et al., 2007). Three forms of depreciation are discussed in the literature: (1) physical degradation such as spoilage in fruits and vegetables (Ma et al., 2019), (ii) functional loss as medicine expires and (3) value loss as in fashion and high-tech products (Pahl \& Voß, 2014). Ma et al. (2019) studied a three-echelon supply chain consists of one supplier, third-party logistics service providers and one retailer that provides seasonal fresh agricultural products to customers where the market demand is dependent on price and freshness of the product. They designed a dynamic game model considering both centralized and decentralized settings. They found that decentralized decision-making could lead to a distortion of order quantity and sales price and it could eventually results in a loss of profit in the supply chain. Depreciation occurs under different time patterns (Hsu, 2000). Hsu (2000) investigate the perishable product's deterioration rate using an economic lot-sizing model and found that the deterioration rate and it's carrying cost in each period is depending on the age of the stock. Studies on the stochastic model, considering both perishability and disruption are limited. However, some authors used basic inventory models such as the newsboy problem to model perishability. Cai \& Zhou (2014) modelled perishability at the exponential cost of decay, incorporating two shelf-life metrics, namely best-before-date and good-until-time, into the supply chain of vegetables where the main transport link is interrupted. Onggo et al. (2019) developed a mixed-integer programming model for an agri-food supply chain with a single supplier with a central warehouse and retailer with a storage facility for the fresh product, which is perishable. They also proposed a simheuristic algorithm for both inventory and routing decisions to minimize the inventory, transportation, food-waste, and stockout costs in the face of stochastic customer demand. Perishability is an important factor in the agriculture supply chain. Therefore, there is a need to develop more robust perishability functions while designing mathematical models.

ASC considered both robust and resilient strategies for managing risk (Leat \& Revoredo-Giha, 2013). Many studies consider dual-sourcing (Guan \& Philpott, 2011; Hou, Zeng \& Sun, 2017) and multiple-sourcing as a robust strategy to manage supply-side risk (Ray \& Jenamani, 2016a). Guan \& Philpott (2011) analysed the back-up supply strategy for a dairy supply chain under milk supply uncertainty. Hou, Zeng \& Sun (2017) studied the dual-souring strategy considering major suppliers and back-up suppliers. When there is risk in major suppliers, they designed a capacity contract between a buyer and a back-up supplier to manage supply-side risk. Ray \& Jenamani (2016a) studied a two-stage perishable product supply chain with a buyer and multiple unreliable suppliers subjected to disruption risk. The buyer faces an uncertain market demand. The authors developed a non-linear optimization model for the buyer's optimal order allocation and supplier selection under supply disruption and demand uncertainty. They further validated the model through a perishable product supply chain. Researchers also consider the resilient strategy for managing risks (Cai \& Zhou, 2014; Ali et al. 2017; Ali et al. 2018; Namdar et al., 2018). Ali et al. (2017) developed a framework to build resilience in small and medium-sized businesses, and their study indicates that the majority of risks originate from factors intrinsic to the supply chain, thereby requiring close supply chain cooperation. Ali et al. (2018) consider a mixed-method approach to develop a model based on empirical evidence of the interplay between cold chain logistics risk, resilience and firm performance in perishable product supply chains. The authors found the critical sources of uncertainties in cold chain logistics and resources indispensable to build resilience. Namdar et al. (2018) consider different types of sourcing strategies such as single sourcing, multiple sourcing, back-up sourcing, spot purchasing, collaboration and visibility to achieve supply chain resilience under disruptions. For a detailed review of the resilient supply chain, the readers can refer to Stone $\&$ Rahimifard (2018). There are very few researchers who consider both robust and resilient strategies (Ivanov et al., 2016; Behzadi et al., 2017). Ivanov et al. (2016) examined a time-critical supply chain in the Australian dairy industry and recovery strategies 
in the context of ripple effects. The authors used a simulation model to compare proactive and reactive approaches to tackle the ripple effect of resilience and flexibility views. Researchers used different types of models such as systems engineering, optimization, simulation modelling etc. for managing risks (Kumar \& Anbanandam; Galli, 2020). Though studies consider both strategies, there still exists the lack of optimization model that includes perishability, demand and price uncertainty together with supply-side risks. An optimization model is built in this paper by considering the exponential perishability function, demand and price uncertainty with supply-side risks.

\section{THE MODEL}

This paper considers a two-stage supply chain consisting of a supplier with their storage facility and demand point with the storage facilities. As there are multiple risks involved in the supplier side such as harvest risk, weather-related risk, production yield risk etc., the supply chain planner has to decide the optimal strategies that maximize his expected profit. The commonly adopted strategy in the agriculture supply chain to manage risks are multiple sourcing, back-up sourcing, and moderating the probability of disruption. In multiple sourcing, if a particular supply node is disrupted, the new supplier is added to the supply base to meet demand. Similarly, in back-up sourcing, the back-up supplier is generally assumed to be reliable, but its cost is high. It is preferred when the main suppliers (unreliable but low cost) are disrupted (Ray \& Jenamani, 2016b). Proactive planning is generally done in the critical node of the supply chain to moderate the probability of disruption. For example, in the agricultural supply chain, design irrigation channels such that it will mitigate the deficiency of rainfall or utilize modern technology planting to reduce the probability of being disrupted by harsh weather (Higgins et al., 2010). Besides that, if nothing can be done (in case of force majeure), we simply have to accept the risk as it is; called the risk acceptance strategy.

The notations for the proposed optimization model are given as follows: The supply variable for the product commodity $k \in K$ at supply location $i \in I$ in period $t \in T$ under scenario $\omega \in \Omega$ is given by $s_{i k t \omega m}$ and risk management strategy $m \in \theta$. The supply-side variable depends on the strategy used; however, other supply chain variables are independent of the strategy used. These variables include $h_{i k t \omega}$ and $h_{j k t \omega}$ (the inventory held at supply facility $i$ or demand facility $j$ in the time period $t$ and scenario $\omega$ ), $x_{i j k t \omega}$ (i.e., the shipment of product $k$ from supply location $i$ to the demand location $j$ in the time period $t$ and scenario $\omega$ ), and $y_{j k t \omega}$ (i.e., the sales of product $k$ at the demand location $j$ in the time period $t$ and scenario $\omega)$. Variables $\varphi_{i}(k, t-1,1), \varphi_{j}(k, t+l(i, j)-1,1), \varphi_{i j}(k, t, l(i, j)$ denote the decay process in different supply chain stages. All the notations are similar to the ones used in the literature (Behzadi et al., 2017). To model perishability, we choose a fractional formulation denoted by $\pi(k)$. The perishability function $\varphi\left(k, t_{0}, " t\right)$ dependent on commodity product, starting time and duration of the product remains in a state given by:

$$
\varphi_{n}\left(k, t_{0}, \Delta t\right)=\varphi_{i j}\left(k, t_{0}, \Delta t\right)=\varphi\left(k, t_{0}, \Delta t\right)=\prod_{t=t_{0}}^{t_{0}+\Delta t}(1-\pi(k))^{\Delta t}, \forall \text { locations } n
$$

The unperished factor is determined by the length of inventory holding and shipping with a constant commodity-dependent loss rate, which is exponential. However, the maximum limit is restricted by a quality barrier. Here, the product unit is based on the unit carton and quantity related parameters and variables are defined by the carton. The model has assumptions such as; all shipments 
are made at the end of a time period; disruptions occur one at a time at all supply regions. The sales price, i.e., price of commodity $k$ in market $j$ a time $t$ under scenario $(\omega)$, is taken from the market and is used as an input parameter. The sales price is assumed to be normally distributed with a mean ( $\mu$ ) and standard deviation $(\sigma)$. Scenario dependent and independent variables are used where the first one is not dependent on scenarios or need to be determined before a situation is realized, and the second one is determined after a situation is realized. There is a fixed cost $\left(f_{m}\right)$ involved in implementing a risk management strategy $\left(z_{m}\right)$ The total cost of implementing risk management strategies is $F\left(z_{m}\right)=\sum_{m \in \theta} f_{m} z_{m}$. Choosing a mixed set of strategies is itself a challenge. To overcome the challenge, all strategies are divided into supply-based and probability-based. The supply-based strategies $m \in \theta^{s}$ affect both the supply cost $c^{s}(i, k, t, m)$ and the supply bounds $\underline{\mathrm{s}}(\mathrm{i}, \mathrm{k}, \mathrm{t}, \omega, m)$ and $\bar{s}(i, k, t, \omega, m)$. Because of the bounds, it does not allow the planner to choose more than one supplybased strategy. The probability-based strategies $m \in \theta^{p r}$ moderates the disruption likelihood $(\operatorname{Pr}(\omega))$ and, conversely, increase the base scenario probability $\left(\operatorname{Pr}\left(\omega_{0}\right)\right.$. Thus, for every $m \in \theta^{p r}$ there occurs probability adjustments $\Delta \operatorname{Pr}(\omega, m)$ for every $\omega \in \Omega$ that affect the expected total profit. For supplybased strategies, to prevent the interaction of the probability adjustments, at most, one probabilitybased strategy can be chosen in a risk management plan. The objective function of the decision-maker is to maximize the expected profit.

Maximize:

$$
\begin{aligned}
& \sum_{m \in \theta} f_{m} z_{m}+\left[\operatorname{Pr}\left(\omega_{0}\right)+\sum_{m \in \theta^{p r}} \Delta \operatorname{Pr}\left(\omega_{0}, m\right) z_{m}\right] P_{\omega_{0}} X\left(\omega_{0}\right) \\
& +\sum_{\omega \in \Omega /\left\{\omega_{0}\right\}}\left[\operatorname{Pr}(\omega)-\sum_{m \in \theta^{p r}} \Delta \operatorname{Pr}(\omega, m) z_{m}\right] P_{\omega}\left(X_{\omega}\right) \\
& =\sum_{m \in \theta} f_{m} z_{m}+\sum_{\omega \in \Omega} \operatorname{Pr}(\omega) P_{\omega}\left(X_{\omega}\right)+\sum_{m \in \theta^{p r}} \Delta \operatorname{Pr}\left(\omega_{0}, m\right) z_{m} P_{\omega_{0}}\left(X_{\omega_{0}}\right) \\
& -\sum_{\omega \in \Omega /\left\{\omega_{0}\right\}} \sum_{m \in \theta^{p r}} \Delta \operatorname{Pr}(w, m) z_{m} P_{\omega}\left(X_{\omega}\right)^{p}
\end{aligned}
$$

For $m \in \theta^{p r}$ :

$$
\sum_{m \in \theta^{p r}} \Delta \operatorname{Pr}\left(\omega_{0}, m\right) z_{m} P_{\omega_{0}}\left(X_{\omega_{0}}\right)-\sum_{\omega \in \Omega /\left\{\omega_{0}\right\}} \sum_{m \in \theta^{p r}} \Delta \operatorname{Pr}(w, m) z_{m} P_{\omega}\left(X_{\omega}\right)
$$

The demand for the perishable product is uniform throughout the year in the respective demand location. That is why we have considered that the demand follows uniform distribution in the range (a,b) for every $j \in J, r \in R, t \in T, \omega \in \Omega$. Therefore, the demand constraint is given by the following equation:

$\bar{d}(j, r, t) \sim U(a, b), \forall j \in J, r \in R, t \in T, \omega \in \Omega$ 
where a: Demand lower bound in the demand location; b: Demand upper bound in the demand location.

The harvesting season of the product is for four months. Therefore, the sales price reaches a specific point in the year due to the lesser supply in some of the months. That is why sales price is assumed to follow a normal distribution with mean $\mu$ and variance $\sigma^{2}$ for every $j \in J, r \in R, t \in T$ and $\omega \in \Omega$. The price uncertainty constraint is given as follows:

$$
p(j, k, t, \omega) \sim N\left(\mu, \sigma^{2}\right), \forall j \in J, k \in K, t \in T, \omega \in \Omega
$$

The optimization model is now formulated to maximize the expected profit as given below:

$$
\begin{aligned}
& \sum_{m \in \theta}-f(m) z_{m}+\sum_{m \in \theta^{p r}} \Delta \operatorname{Pr}\left(\omega_{0}, m\right) z_{m} P_{\omega_{0}}\left(X_{\omega_{0}}\right) \\
& -\sum_{\omega \in \Omega \backslash\left\{\omega_{0}\right\}} \sum_{m \in \theta^{p r}} \Delta \operatorname{Pr}(\omega, m) z_{m} P_{\omega}\left(X_{\omega}\right)+\sum_{\omega \in \Omega} \operatorname{Pr}(\omega) P_{\omega}\left(X_{\omega}\right)
\end{aligned}
$$

The constraints are scenario-dependent profit, flow balance constraints, perishability constraints, market capacity constraint, demand and price constraints.

\section{NUMERICAL ILLUSTRATION}

In this section, numerical analysis is performed to gain further insights from the model using the input data from Behzadi et al. (2017). The mixed-integer programming problem is solved by using IBM-ILOG CPLEX, Windows 10, Intel Core i5-5200 CPU running at 2.2 GHz and $8 \mathrm{~GB}$ of RAM. For demand uncertainty and price uncertainty case, some of the data are modified. The sales price in the three markets is assumed to follow a normal distribution with the mean of 9.39, 16.57 and 14.05 , respectively and their standard deviations following the 3 -sigma rule. The assumption of the distribution is inspired by the fact that the prices rise to a certain peak value once in a year. The upper bound of the demand commodity is assumed to be uniform distribution as its demand almost remains uniform throughout the year. Table 1 shows the performance improvement of different strategies under harvest disruption and yield disruption.

\section{Harvest Disruption Under Demand and Price Uncertainty}

As shown in the Table, column 1 shows the available strategy ( $2^{3}$ no. of strategy combinations: Risk acceptance (No strategy), three strategies together, two strategies together and individual strategy). A risk acceptance strategy is used as a base for comparison with other available strategies or combinations of strategies. Without considering any risk management strategy (risk acceptance strategy), the expected profit in harvest disruption is 1005.089. Considering all the three strategies together in harvest disruption (Table 1, row 2, Column 2-3), the improvement in expected profit is 9.67\% as compared to 3.13\% in Behzadi et al. (2017)'s work without considering demand and price uncertainty. It shows that the combination of all the strategies realizes the price and demand uncertainty better and provide good coverage against the risk of declining in the expected profit. The best improvement over subsets of two strategies (Mu. Sup. \& Mod. Pr.) is 3.64\%, which is slightly greater than the previous result, which was $2.80 \%$. When a single strategy is available, the best performance is achieved by utilizing the BU. Sup. i.e., 6.47\% improvement. When only Mod. Pr. strategy is implemented, it reduces the expected profit by $1.49 \%$. It signifies that Mod. Pr. strategy should be implemented in conjunction with other strategies as they are applied before the situation is actually realized. It makes the correct estimation of the scenario a bit difficult, and thus the negative improvement signifies that. 
Table 1. Performance improvement under harvest disruption and yield disruption

\begin{tabular}{|c|c|c|c|c|}
\hline \multirow{2}{*}{ Available Strategies } & \multicolumn{2}{|c|}{ Harvest Disruption } & \multicolumn{2}{c|}{ Yield Disruption } \\
\cline { 2 - 5 } & E[Profit] & Improvement & E[Profit] & Improvement \\
\hline None (Risk Acceptance) & 1005.089 & - & 1019.35 & - \\
\hline BU. Sup., Mod. Pr. \& Mu. Sup. & 1102.25 & 9.66 & 1173.91 & 15.16 \\
\hline Mu. Sup. \& Mod. Pr. & 1041.64 & 3.63 & 1120.96 & 9.96 \\
\hline BU. Sup. \& Mu. Sup. & 1030.68 & 2.54 & 1156.97 & 13.50 \\
\hline BU. Sup. \& Mod. Pr. & 1051.54 & 4.62 & 1094.63 & 7.38 \\
\hline Mod. Pr. & 991.02 & -1.39 & 1007.80 & -1.13 \\
\hline Mu. Sup. & 1021.04 & 1.58 & 1020.46 & 0.10 \\
\hline BU. Sup. & 1070.19 & 6.47 & 1042.39 & 2.26 \\
\hline
\end{tabular}

\section{Yield Disruption Under Demand and Price Uncertainty}

The performance improvement under yield disruption is given in Table 1 (Column 2-3). Similar to harvest disruption, different strategies are considered. In risk acceptance strategy under yield disruption, the expected profit is 1019.35 . The best improvement is observed when three strategies are considered together ( $15.16 \%$ improvement). If we consider any two strategies out of three, the best improvement is $13.5 \%$ considering back-up and multiple sourcing. If only a single strategy is available, the best strategy is the back-up supplier, where the performance is $2.26 \%$. If Mod. Pr. strategy utilized alone, it decreases the profit by $1.13 \%$. It signifies that Mod. Pr. strategy should be implemented in conjunction with other strategies as they are applied before the situation is actually realized.

\section{SENSITIVITY ANALYSIS}

The effect of perishability on harvest disruption performance improvement under different risk management strategies is given in Figure (1-7). As shown in Figure 1, the higher the rate of perishability, the performance improvement in the expected profit is more compared to the risk acceptance strategy. It is intuitive since a higher percentage of perishability means greater uncertainty, and thus more advantages in the implementation of risk management strategies. Considering the combination of two strategies: Mu. Sup. \& Mod. Pr. (Figure 2), BU. Sup. \& Mu. Sup. (Figure 3), BU. Sup. \& Mod. Pr. (Figure 4), if the perishability increases, the improvement is better in multiple suppliers with moderating probability (Figure 2). Similarly, when the effect of perishability on percentage improvement is considered under a single strategy, the moderating probability strategy seems to be less effective with a high level of perishability (Figure 5). That's because the strategy reduces the probability of disruption and increases the likelihood of a base scenario. The improvement in multiple supplier strategy is better up to perishability $35 \%$, and then it sharply decreases afterward (Figure 6). Under the back-up strategy, the improvement with perishability is better than the moderating probability (Figure 7). At high perishability rates, the strategy used in conjunction shows a more significant improvement in the expected profit. The combination of all three strategies results in the significant improvement in the expected profit at higher perishability rates and thus is most sensitive to the perishability.

The effect of perishability on yield disruption performance improvement under different risk management strategies is given in Figure (8-14). As shown in Figure 8, under yield disruption, as the vulnerability increases with a high rate of perishability, by implementing all risk management strategies together (BU. Sup., Mod. Pr. \& Mu. Sup.), the expected profit of the decision-maker increases. 
Figure 1. Perishability vs. harvest disruption performance improvement under BU. Sup., Mod. Pr. \& Mu. Sup

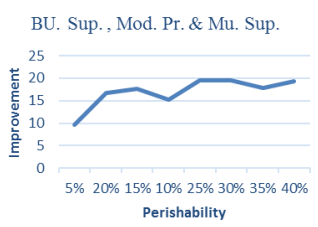

Figure 2. Perishability vs. harvest disruption performance improvement under Mu. Sup. \& Mod. Pr

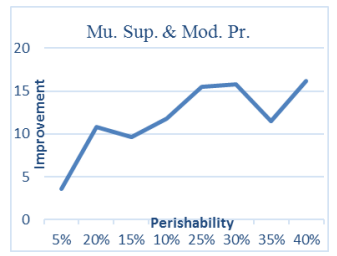

Figure 3. Perishability vs. harvest disruption performance improvement under BU. Sup. \& Mu. Sup

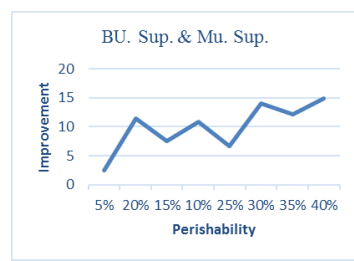

Figure 4. Perishability vs. harvest disruption performance improvement under BU. Sup. \& Mod. Pr

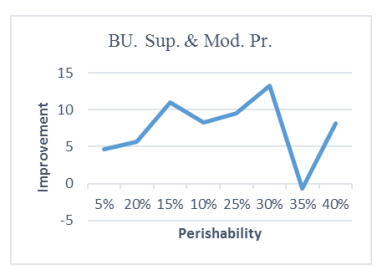

Figure 5. Perishability vs. harvest disruption performance improvement under Mod. $\mathrm{Pr}$

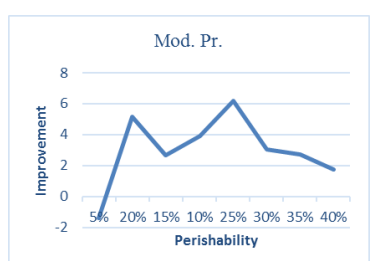


Figure 6. Perishability vs. harvest disruption performance improvement under Mu. Sup

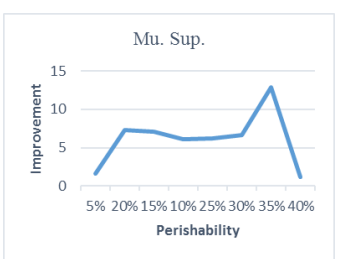

Similarly, when the decision-maker adopts two strategies together, multiple suppliers with moderating probability (Mu. Sup. \& Mod. Pr.) strategy (Figure 9) perform better in a higher perishability rate than the other two strategies. Though in back-up suppliers and multiple supplier risk management strategies, the improvement is decreasing after the percentage of perishability reaches $30 \%$ (Figure 10). Similarly, in a back-up supplier with moderating probability risk management strategies (Figure 11), as the perishability rate increases, the performance improvement in profit is not that good as compared to the other two combinations of strategies. Yield disruption performance improvement under a single risk management strategy is given in Figure (12-14). As shown in Figure 12, the moderating probability strategy is also a bit effective at high perishability rates, which is similar to the case in harvest disruption scenario. At high perishability rates, this strategy has almost zero improvements in the expected profit. Therefore, it is recommended that under yield disruption, when the rate of perishability is high, the moderating probability strategy is not beneficial as no further improvement in the profit is observed. In multiple supplier strategies under harvest disruption, if the perishability rate increases, there is a slight improvement in the performance compared to the moderating probability (Figure 13). It may be due to the fact that if there is yield disruption and also the product is highly perishable, to cope with the uncertain market demand and also supply-side risks, it's better to have multiple suppliers in the supply base to cater the need. Similarly, as shown in Figure 14, under harvest disruption, if the product is highly perishable in nature, the back-up supplier strategy will be useful if all suppliers in a single location fail to meet both supply and demand-side risks. Comparing the three individual strategies, performance improvement under the back-up supplier strategy is better than the other two. A high perishability rate, these strategies used in the conjunction shows a slight improvement in expected profit as opposed to the harvest disruption where the improvement in the expected profit is considerable. In the case of yield disruption with price and demand uncertainty, there is a slight improvement in the expected profit with higher rates of perishability. Therefore, these strategies are less sensitive to perishability under yield disruption.

\section{MANAGERIAL INSIGHTS}

Several managerial insights can be drawn from the results discussed above for agricultural supply chain risk management under demand and price uncertainty. As both robustness and resilience are of nearly the same as robustness allows the supply to withstand any kind disruptions. In contrast, resilience

Figure 7. Perishability vs. harvest disruption performance improvement under BU. Sup

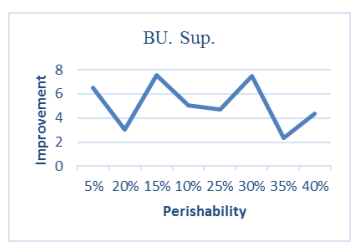


Figure 8. Perishability vs. yield disruption performance improvement under BU. Sup., Mod. Pr. \& Mu. Sup

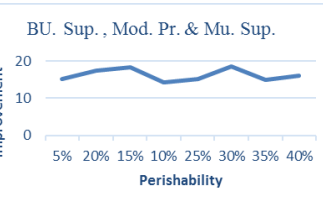

Figure 9. Perishability vs. yield disruption performance improvement under Mu. Sup. \& Mod. Pr

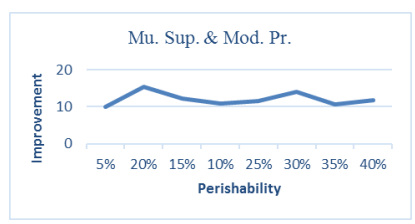

Figure 10. Perishability vs. yield disruption performance improvement under BU. Sup. \& Mu. Sup

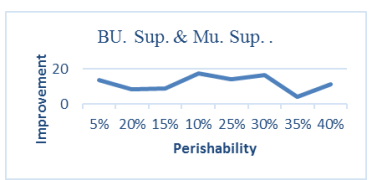

Figure 11. Perishability vs. yield disruption performance improvement under BU. Sup. \& Mod. Pr

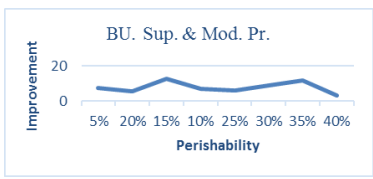

Figure 12. Perishability vs. yield disruption performance improvement under Mod. $\mathrm{Pr}$

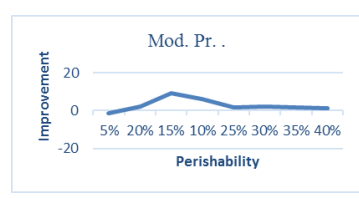

Figure 13. Perishability vs. yield disruption performance improvement under Mu. Sup

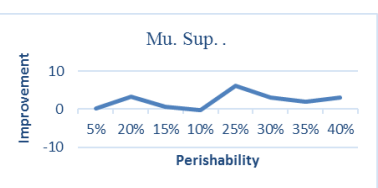


Figure 14. Perishability vs. yield disruption performance improvement under BU. Sup

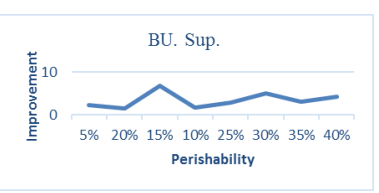

ensures quick recovery after failing to mitigate the risks, and they cannot be applied individually to mitigate the risks in the supply chain. Supply chain planners should consider a mixed combination of all or both strategies while planning to manage the risks. It is also quite evident from the results as mixed strategies (all three strategies together) provide more expected profits as compared to the strategy when applied individually. The effectiveness of the strategy is again scenario dependent. For example, the back-up supplier strategy is very effective during the yield disruption, but it is not as effective during harvest disruption. Also, if a planner is only trying to reduce the impact of harsh weather by using any moderating probability strategy under yield disruption, the strategy alone may not be beneficial as it reduces the improvement in profit. It gives clear evidence that a single strategy is inadequate to provide the solution in all types of risk scenarios. Companies must, therefore, consider all risk management strategies available that can address risks and vulnerabilities in their supply chain. Similar insights are found in Pettit's (2008) empirical study. Perishability has a significant impact on implementing risk management strategies. The agricultural supply chain will suffer a substantial loss if the planners neglect these risks as the product; they deal with are highly perishable in nature. The optimal strategy selection resulted from the model provides a strategic direction on planning effective risk management strategies for the sustainability of agriculture supply chains. Thus, the agriculture supply chains need to modify their model to the proposed optimization model and customize parameter settings accordingly for generating a risk management plan that suits their unique business policies.

\section{CONCLUSION AND FUTURE SCOPE}

Agricultural products have unique features that make risk management in agricultural supply chains (ASC) quite difficult. The existing literature has researched on ASC risk management to a very limited extent, particularly in the field of perishability in risk management modelling. This study develops an optimization model by analysing the effectiveness of risk management strategies on the performance of the agricultural supply chain under demand and price uncertainty together. The developed model is applied to a perishable product supply chain. The performance of the robust and resilient strategies is analysed under different risk scenarios. To the best of author's knowledge, it is among the first study which considers supply-side risks with demand and price uncertainty together through robust and resilient strategies for managing agricultural supply chain risk. The model also finds perishability function more realistically. It also studies the impact of perishability on harvest time disruption and yield disruption performance improvement under various sets of risk management strategies. It is observed from the analysis that, the perishability of the product has a significant effect on the benefits of implementing risk management strategies. It is intuitive as, the higher the rate of perishability, the more useful it is to mitigate disruptions due to the increased vulnerabilities and risks. It also suggests that the greater is the loss for the supply chains of agricultural products that are highly perishable (e.g., fresh fruit and vegetables) if the disruption risks are ignored. The mixed combination of both robust and resilient strategies is also effective in managing agricultural supply chain risk, and a single approach is inadequate to provide solutions in all types of risk scenarios.

This research has its limitations. Though the model is developed considering demand and price uncertainty, theoretical insights of the model are not derived due to many uncertainty factors. More extensive research on agricultural supply chain risk with theoretical insights as well as perishability 
issues can be considered in the future. Offering the discounted price and the price promotion to more perishable products can be another interesting extension. One can explore other risk management strategies and implementation of disruptive information and communication technologies such as Artificial Intelligence (AI), Internet of Thing (IoT), Cloud Computing, Big data analytics, and Blockchain technology (Kamble et al., 2020) for traceability improvement, and machine learning (ML) algorithm for providing real-time analytic insights for pro-active data-driven decision-making for improving agricultural productivity and sustainability (Sharma et al., 2020) and precision agriculture or smart farming practices using technology such as Geographic Information System (Sharma et al., 2018). Another extension could be consideration of risk attitude of the decision-maker such as risk-averse behaviour of the decision-maker using the methods such as mean-variance theory, mean standard deviation and conditional value at risk and risk-seeking decision-makers choice while designing the risk management strategy.

\section{ACKNOWLEDGMENT}

This research is supported by the Indian Institute of Management Ranchi, India [Seed Money Grant 2019]. 


\section{REFERENCES}

Ali, I., Nagalingam, S., \& Gurd, B. (2017). Building resilience in SMEs of perishable product supply chains: Enablers, barriers and risks. Production Planning and Control, 28(15), 1236-1250. doi:10.1080/09537287.2 017.1362487

Ali, I., Nagalingam, S., \& Gurd, B. (2018). A resilience model for cold chain logistics of perishable products. International Journal of Logistics Management, 29(3), 922-941. doi:10.1108/IJLM-06-2017-0147

Anilkumar, E. N., \& Sridharan, R. (2019). Sustainable Supply Chain Management: A Literature Review and Implications for Future Research. International Journal of System Dynamics Applications, 8(3), 15-52. doi:10.4018/IJSDA.2019070102

Behzadi, G., O’Sullivan, M. J., Olsen, T. L., Scrimgeour, F., \& Zhang, A. (2017). Robust and resilient strategies for managing supply disruptions in an agribusiness supply chain. International Journal of Production Economics, 191, 207-220. doi:10.1016/j.ijpe.2017.06.018

Behzadi, G., O’Sullivan, M. J., Olsen, T. L., \& Zhang, A. (2018). Agribusiness supply chain risk management: A review of quantitative decision models. Omega, 79, 21-42. doi:10.1016/j.omega.2017.07.005

Behzadi, G., O’Sullivan, M. J., Olsen, T. L., \& Zhang, A. (2018). Allocation flexibility for agribusiness supply chains under market demand disruption. International Journal of Production Research, 56(10), 3524-3546. do i:10.1080/00207543.2017.1349955

Berger, P. D., Gerstenfeld, A., \& Zeng, A. Z. (2004). How many suppliers are best? A decision-analysis approach. Omega, 32(1), 9-15. doi:10.1016/j.omega.2003.09.001

Borodin, V., Bourtembourg, J., Hnaien, F., \& Labadie, N. (2016). Handling uncertainty in agricultural supply chain management: A state of the art. European Journal of Operational Research, 254(2), 348-359. doi:10.1016/j. ejor.2016.03.057

Boyabatl, O., Nguyen, J., \& Wang, T. (2017). Capacity management in agricultural commodity processing and application in the palm industry. Manufacturing \& Service Operations Management, 19(4), $551-567$. doi:10.1287/msom.2017.0624

Cai, X., \& Zhou, X. (2014). Optimal policies for perishable products when transportation to export market is disrupted. Production and Operations Management, 23(5), 907-923. doi:10.1111/poms.12080

Christopher, M., \& Peck, H. (2004). Building the resilient supply chain. Academic Press.

Gafi, E. G., \& Javadian, N. (2018). A System Dynamics Model for Studying the Policies of Improvement of Chicken Industry Supply Chain. International Journal of System Dynamics Applications, 7(4), 20-37. doi:10.4018/ IJSDA.2018100102

Galli, B. J. (2020). Application of Systems Engineering to Risk Management: A Relational Review. International Journal of System Dynamics Applications, 9(2), 1-23. doi:10.4018/IJSDA.2020040101

Gebreslassie, B. H., Yao, Y., \& You, F. (2012). Design under uncertainty of hydrocarbon biorefinery supply chains: Multiobjective stochastic programming models, decomposition algorithm, and a comparison between CVaR and downside risk. AIChE Journal. American Institute of Chemical Engineers, 58(7), 2155-2179. doi:10.1002/aic.13844

Guan, Z., \& Philpott, A. B. (2011). A multistage stochastic programming model for the New Zealand dairy industry. International Journal of Production Economics, 134(2), 289-299. doi:10.1016/j.ijpe.2009.11.003

Guma, I. P., Rwashana, A. S., \& Oyo, B. (2018). Food Security Indicators for Subsistence Farmers Sustainability: A System Dynamics Approach. International Journal of System Dynamics Applications, 7(1), 45-64. doi:10.4018/ IJSDA.2018010103

Higgins, A. J., Miller, C. J., Archer, A. A., Ton, T., Fletcher, C. S., \& McAllister, R. R. J. (2010). Challenges of operations research practice in agricultural value chains. The Journal of the Operational Research Society, 61(6), 964-973. doi:10.1057/jors.2009.57 
Hou, J., Zeng, A. Z., \& Sun, L. (2017). Back-up sourcing with capacity reservation under uncertain disruption risk and minimum order quantity. Computers \& Industrial Engineering, 103, 216-226. doi:10.1016/j.cie.2016.11.011

Hsu, V. N. (2000). Dynamic economic lot size model with perishable inventory. Management Science, 46(8), 1159-1169. doi:10.1287/mnsc.46.8.1159.12021

Iqbal, M. C., \& Shalij, P. R. (2019). Supply Chain Risk Assessment in the Ornamental Fish Supply Chain. International Journal of System Dynamics Applications, 8(2), 36-50. doi:10.4018/IJSDA.2019040103

Ivanov, D., Sokolov, B., Solovyeva, I., Dolgui, A., \& Jie, F. (2016). Dynamic recovery policies for time-critical supply chains under conditions of ripple effect. International Journal of Production Research, 54(23), 7245-7258. doi:10.1080/00207543.2016.1161253

Jones, P. C., Kegler, G., Lowe, T. J., \& Traub, R. D. (2003). Managing the seed-corn supply chain at Syngenta. Interfaces, 33(1), 80-90. doi:10.1287/inte.33.1.80.12718

Kamble, S. S., Gunasekaran, A., \& Sharma, R. (2020). Modeling the blockchain enabled traceability in agriculture supply chain. International Journal of Information Management, 52, 101967. doi:10.1016/j.ijinfomgt.2019.05.023

Kazaz, B., \& Webster, S. (2011). The impact of yield-dependent trading costs on pricing and production planning under supply uncertainty. Manufacturing \& Service Operations Management, 13(3), 404-417. doi:10.1287/ msom. 1110.0335

Kim, J., Realff, M. J., \& Lee, J. H. (2011). Optimal design and global sensitivity analysis of biomass supply chain networks for biofuels under uncertainty. Computers \& Chemical Engineering, 35(9), 1738-1751. doi:10.1016/j. compchemeng.2011.02.008

Klibi, W., \& Martel, A. (2012). Modeling approaches for the design of resilient supply networks under disruptions. International Journal of Production Economics, 135(2), 882-898. doi:10.1016/j.ijpe.2011.10.028

Komarek, A. M., De Pinto, A., \& Smith, V. H. (2020). A review of types of risks in agriculture: What we know and what we need to know. Agricultural Systems, 178, 102738. doi:10.1016/j.agsy.2019.102738

Kumar, A., \& Anbanandam, R. (2019). Multimodal Freight Transportation Strategic Network Design for Sustainable Supply Chain: An OR Prospective Literature Review. International Journal of System Dynamics Applications, 8(2), 19-35. doi:10.4018/IJSDA.2019040102

Leat, P., \& Revoredo-Giha, C. (2013). Risk and resilience in agri-food supply chains: The case of the ASDA PorkLink supply chain in Scotland. Supply Chain Management, 18(2), 219-231. doi:10.1108/13598541311318845

Ma, X., Wang, S., Islam, S. M., \& Liu, X. (2019). Coordinating a three-echelon fresh agricultural products supply chain considering freshness-keeping effort with asymmetric information. Applied Mathematical Modelling, 67, 337-356. doi:10.1016/j.apm.2018.10.028

Mirzapour Al-e-hashem, S. M. J., Malekly, H., \& Aryanezhad, M. B. (2011). A multi-objective robust optimization model for multi-product multi-site aggregate production planning in a supply chain under uncertainty. International Journal of Production Economics, 134(1), 28-42. doi:10.1016/j.ijpe.2011.01.027

Namdar, J., Li, X., Sawhney, R., \& Pradhan, N. (2018). Supply chain resilience for single and multiple sourcing in the presence of disruption risks. International Journal of Production Research, 56(6), 2339-2360. doi:10.1 080/00207543.2017.1370149

Onggo, B. S., Panadero, J., Corlu, C. G., \& Juan, A. A. (2019). Agri-food supply chains with stochastic demands: A multi-period inventory routing problem with perishable products. Simulation Modelling Practice and Theory, 97, 101970. doi:10.1016/j.simpat.2019.101970

Pahl, J., \& Voß, S. (2014). Integrating deterioration and lifetime constraints in production and supply chain planning: A survey. European Journal of Operational Research, 238(3), 654-674. doi:10.1016/j.ejor.2014.01.060

Pettit, T. J. (2008). Supply chain resilience: development of a conceptual framework, an assessment tool and an implementation process (Doctoral dissertation). Ohio State Univ Columbus.

Ray, P., \& Jenamani, M. (2013). Sourcing under supply disruption with capacity-constrained suppliers. Journal of Advances in Management Research, 10(2), 192-205. doi:10.1108/JAMR-05-2013-0032 
Ray, P., \& Jenamani, M. (2016). Sourcing decision under disruption risk with supply and demand uncertainty: A newsvendor approach. Annals of Operations Research, 237(1-2), 237-262. doi:10.1007/s10479-014-1649-8

Ray, P., \& Jenamani, M. (2016). Mean-variance analysis of sourcing decision under disruption risk. European Journal of Operational Research, 250(2), 679-689. doi:10.1016/j.ejor.2015.09.028

Sharma, R., Kamble, S. S., \& Gunasekaran, A. (2018). Big GIS analytics framework for agriculture supply chains: A literature review identifying the current trends and future perspectives. Computers and Electronics in Agriculture, 155, 103-120. doi:10.1016/j.compag.2018.10.001

Sharma, R., Kamble, S. S., Gunasekaran, A., Kumar, V., \& Kumar, A. (2020). A systematic literature review on machine learning applications for sustainable agriculture supply chain performance. Computers \& Operations Research, 119, 104926. doi:10.1016/j.cor.2020.104926

Sodhi, M. S., Son, B. G., \& Tang, C. S. (2012). Researchers' perspectives on supply chain risk management. Production and Operations Management, 21(1), 1-13. doi:10.1111/j.1937-5956.2011.01251.x

Stone, J., \& Rahimifard, S. (2018). Resilience in agri-food supply chains: A critical analysis of the literature and synthesis of a novel framework. Supply Chain Management, 23(3), 207-238. doi:10.1108/SCM-06-2017-0201

Sunder, S. (2018, January 29). India economic survey 2018: Farmers gain as agriculture mechanisation speeds up, but more R\&D needed. Financial Express. https://www.financialexpress.com/budget/india-economic-survey2018-for-farmers agriculture-gdp msp/1034266/

Tan, B., \& Çömden, N. (2012). Agricultural planning of annual plants under demand, maturation, harvest, and yield risk. European Journal of Operational Research, 220(2), 539-549. doi:10.1016/j.ejor.2012.02.005

Tang, C. S. (2006). Perspectives in supply chain risk management. International Journal of Production Economics, 103(2), 451-488. doi:10.1016/j.ijpe.2005.12.006

Thron, T., Nagy, G., \& Wassan, N. (2007). Evaluating alternative supply chain structures for perishable products. International Journal of Logistics Management, 18(3), 364-384. doi:10.1108/09574090710835110

Wiedenmann, S., \& Geldermann, J. (2015). Supply planning for processors of agricultural raw materials. European Journal of Operational Research, 242(2), 606-619. doi:10.1016/j.ejor.2014.10.021

Zhao, G., Liu, S., Lopez, C., Chen, H., Lu, H., Mangla, S. K., \& Elgueta, S. (2020). Risk analysis of the agrifood supply chain: A multi-method approach. International Journal of Production Research, 1-26. doi:10.10 80/00207543.2020.1713416

Pritee Ray $(P h D)$ is an assistant professor in the area of operations management at the Indian Institute of Management Ranchi. She obtained her doctoral degree from IIT Kharagpur. Her broad area of research is supply chain risk management. She published her research work in top tier international journals such as EJOR, ANOR, etc. and many international conferences. She acts as ad-hoc reviewers in many international journals and conferences. She worked in academia for more than seven years. Her research and teaching interests include supply chain risk management, supply chain coordination, project management, operations research, operations management. 